\title{
Analisis Kekuatan Perkerasan Landasan Pacu Bandar Udara Juanda dengan Metode FAA dan Software COMFAA
}

\author{
Istiar $^{1 *}$, S. Kamilia Aziz ${ }^{2}$ \\ Departemen Teknik Sipil, Institut Teknologi Sepuluh Nopember, Surabaya ${ }^{1}$, Departemen Infrastruktur Teknik Sipil, Institut Teknologi \\ Sepuluh Nopember, Surabaya ${ }^{2}$ \\ Koresponden*,Email: istiar@yahoo.com
}

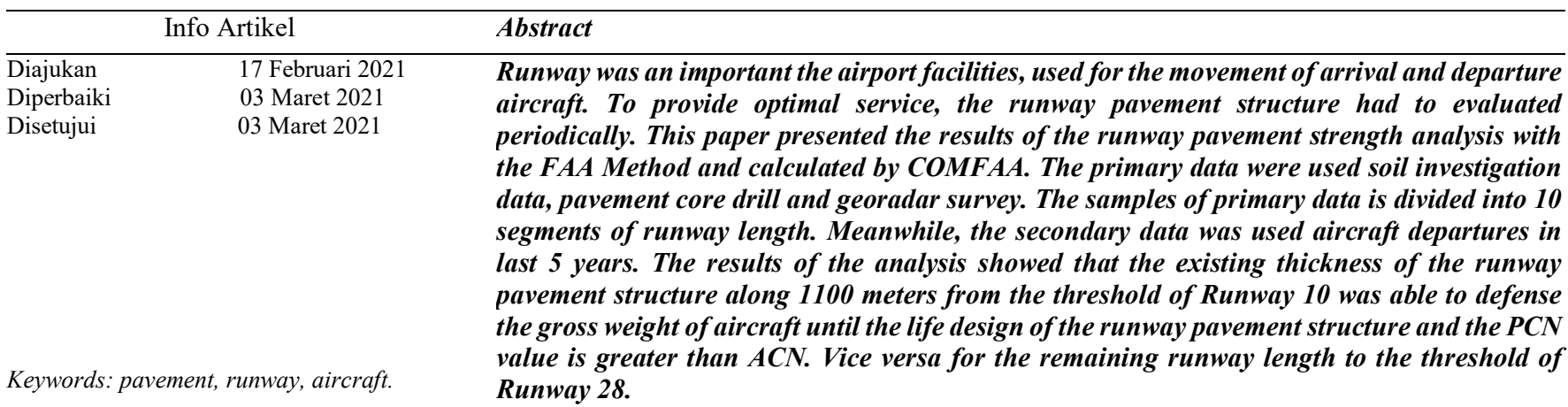

\begin{abstract}
Abstrak
Landasan pacu bandar udara harus diperiksa kekuatan strukturnya secara berkala agar mampu mengakomodasi pergerakan keberangkatan dan kedatangan pesawat terbang secara optimal. Makalah ini memaparkan hasil analisis kekuatan perkerasan landasan pacu Bandara Udara Juanda dengan Metode FAA dan Software COMFAA. Data primer yang digunakan adalah data penyeledikian tanah, hasil coring perkerasan dan survey georadar. Jumlah sampel data primer terbagi dalam 10 segmen panjang landasan pacu. Data sekunder yang digunakan adalah data keberangkatan pesawat terbang dalam 5 tahun terakhir. Hasil analisis menunjukkan bahwa struktur perkerasan landasan pacu sepanjang 1100 meter dari ujung R10 masih mampu menahan beban pesawat terbang. Pada segmen tersebut mempunyai nilai PCN lebih besar dibanding ACN, sedangkan hasil sebaliknya untuk sisa panjang landasan pacu hingga ujung R28.
\end{abstract}

Kata kunci: perkerasan, landasan pacu,

\section{Pendahuluan}

Salah satu fasilitas sisi udara yang berperan penting dalam kegiatan keberangkatan dan kedatangan pesawat terbang pada suatu bandar udara adalah landasan pacu pesawat terbang. Saah satu komponen teknis yang harus diperhatikan agar landas pacu suatu bandar udara dapat berfungsi optimal adalah perkerasan dari landas pacu tersebut. Informasi jenis kontruksi dan kekuatan suatu perkerasan bandar udara dinyatakan dalam pavement classification number ( $\mathrm{PCN})$.

Landasan pacu bandar udara harus diperiksa kekuatan strukturnya secara berkala agar mampu mengakomodasi pergerakan keberangkatan dan kedatangan pesawat terbang secara optimal [4]. Pergerakan keberangkatan dan kedatangan pesawat terbang menyebabkan sistem perkerasan menjadi lelah atau fatigue [6]. Pada tahun 2020, PT. Angkasa Pura (Persero) Bandar Udara Juanda berencana melakukan lapis ulang perkerasan landasan pacu Bandar Udara Juanda. Sebelum dilakukan lapis ulang, perkerasan landasan pacu akan diuji kekuatnnya agar pekerjaan lapis ulang perkerasan bisa optimal dan efisien.

Maksud dari penulisan makalah ini adalah untuk mengetahui kekuatan struktur perkerasan landasan pacu Bandar Udara Juanda, yang selanjutnya informasi tersebut dapat digunakan sebagai dasar kebijakan yang akan diambil terkait kondisi perkerasan landasan pacu Bandar Udara Juanda, misalkan apakah perlu perbaikan terhadap perkerasan landasan pacu atau cukup pembatasan teknis operasional pesawat terbang pada Bandar Udara Juanda.

\section{Metode}

Adapun tahapan analisis kekuatan perkerasan landasan pacu Bandar Udara Juanda dengan Metode FAA dan Software COMFAA dapat dilihat pada bagan alir Gambar 1. Menurut Gambar 1, data yang dibutuhkan untuk menganalisis kekuatan perkerasan landasan pacu Bandar Udara Juanda yakni data struktur perkerasan landasan pacu eksisting dan 
data keberangkatan pesawat terbang di Bandar Udara Juanda. Untuk data struktur perkerasan landasan pacu eksisting meliputi tebal lapisan, material perkerasan dan daya dukung tanah dasar. Sedangkan data keberangkatan pesawat terbang di Bandar Udara Juanda yang digunakan adalah data keberangkatan pesawat terbang di Bandar Udara Juanda dalam 5 (lima) tahun terakhir.

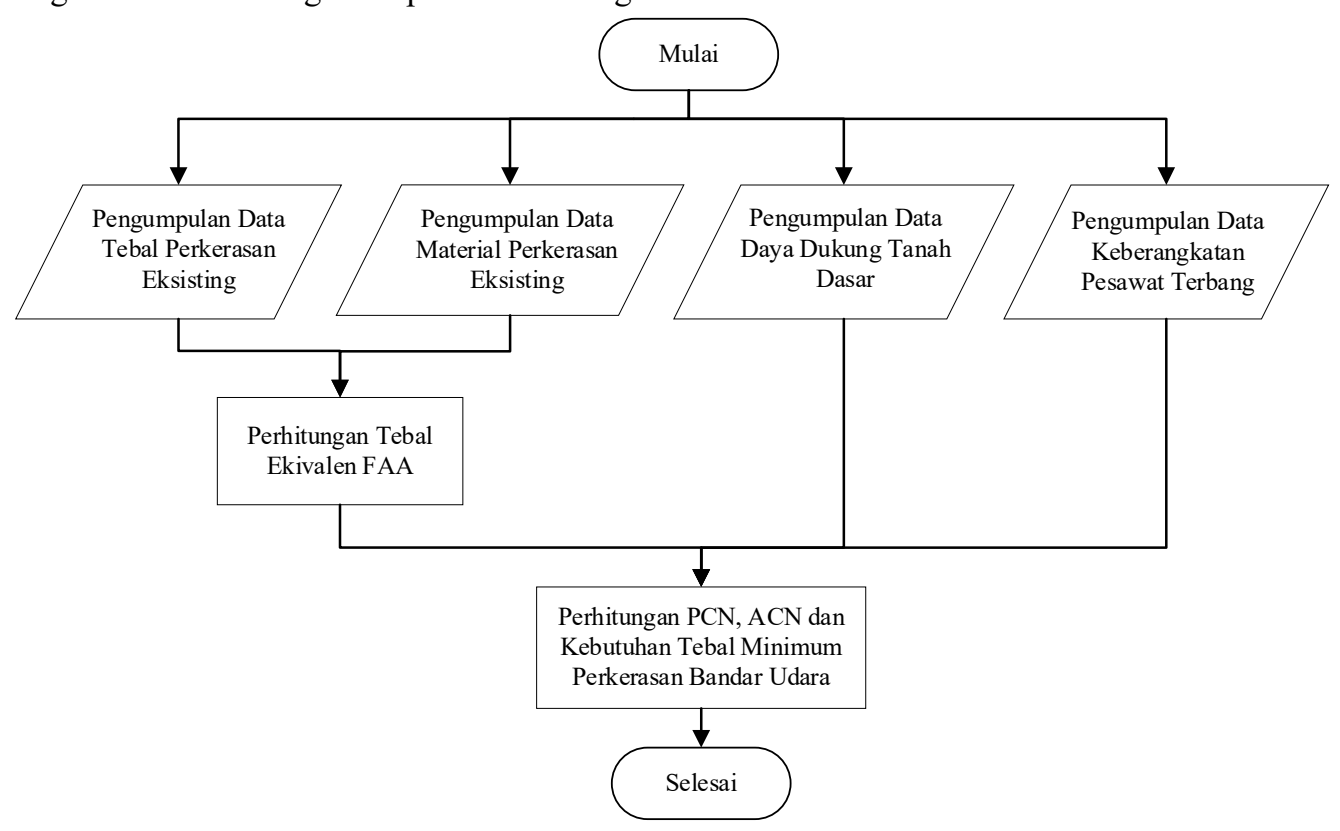

Gambar 1. Bagan Alir Tahapan Analisis Kekuatan Perkerasan Bandara Udara Juanda

Tahap awal analisis data adalah analisis tebal perkerasan eksisting menjadi tebal perkerasan ekivalen FAA. Analisis tebal ekivalen FAA menggunakan bantuan Software MS Excel (lihat Gambar 2) yang diunduh gratis di website www.faa.gov. Selanjutnya tebal perkerasan ekivalen FAA akan menjadi input data pada analisis PCN dengan menggunakan Software COMFAA. Untuk tampilan Software COMFAA dapat dilihat pada Gambar 3.

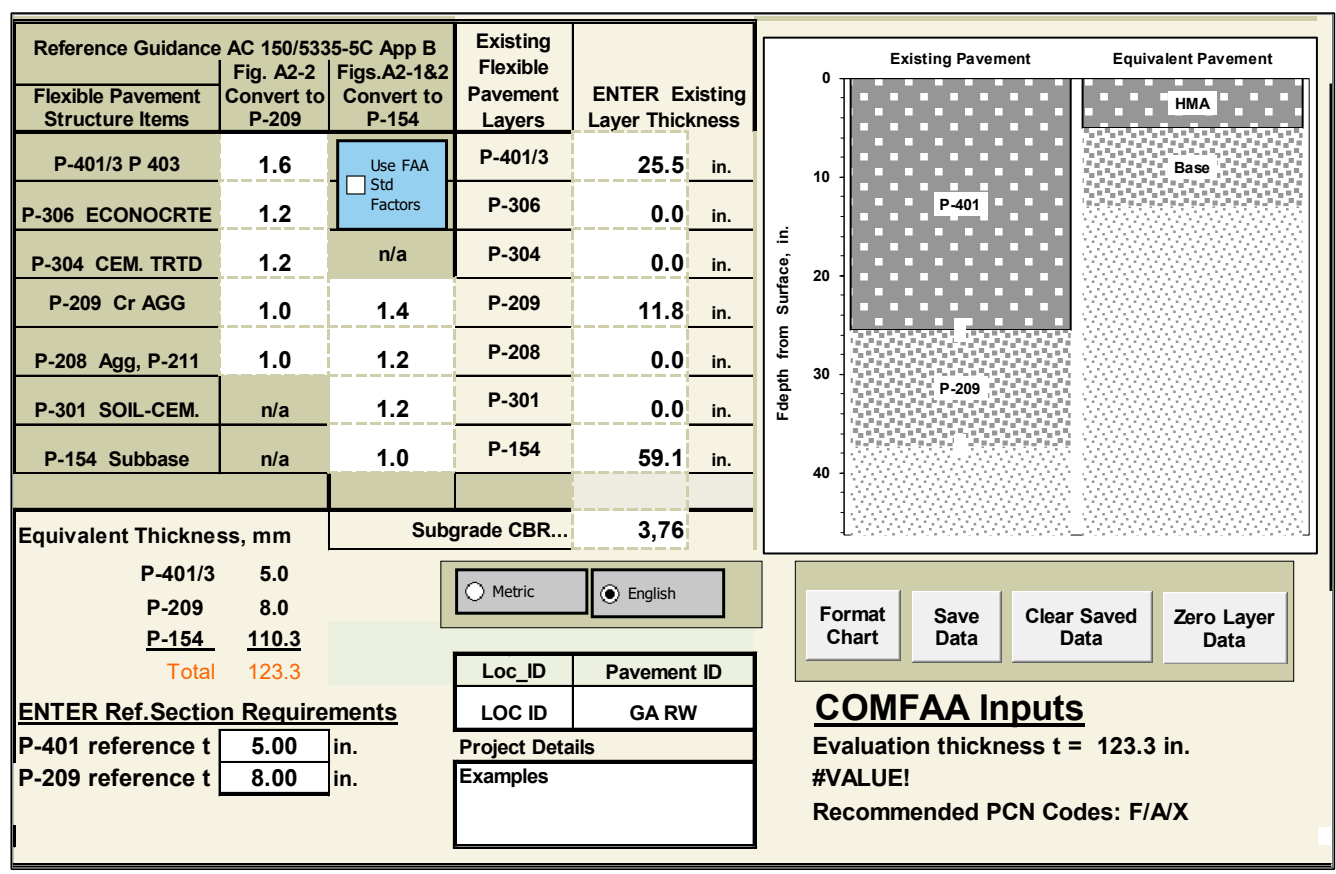

Gambar 2. Software MS Excel Untuk Perhitungan Tebal Perkerasan Ekivalen FAA 


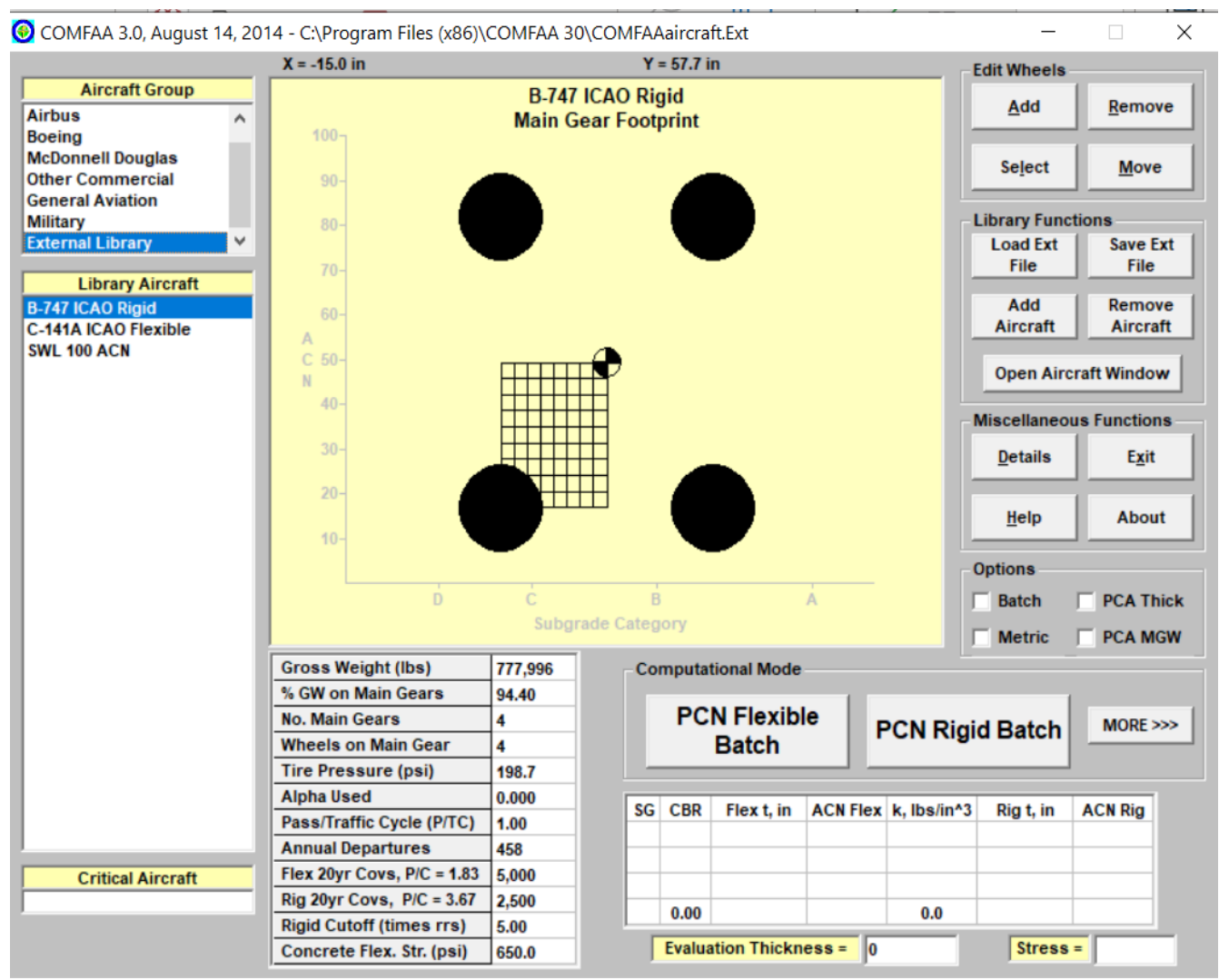

Gambar 3. Software MS Excel Untuk Perhitungan Tebal Perkerasan Ekivalen FAA

\section{Hasil dan Pembahasan}

Sebelum pengumpulan data, landasan pacu Bandar Udara Juanda dibagi menjadi 10 (sepuluh) segmen. Setiap segmen akan diambil sampel data material perkerasan hasil coring perkerasan landasan pacu hingga kedalaman 3 meter. Selain itu, pada saat coring perkerasan landasan pacu, juga diperiksa nilai CBR masing-masing material perkerasan hingga tanah dasar. Untuk pembagian segmen landasan pacu Bandar Udara Juanda dari ujung landasan pacu R10 adalah sebagai berikut:

- Segmen 1 : STA 0+000 s.d. STA 0+300

- Segmen 2 : STA 0+300 s.d. STA 0+564

- Segmen 3 : STA 0+564 s.d. STA 0+820

- Segmen 4 : STA 0+820 s.d. STA 1+100

- Segmen 5 : STA $1+100$ s.d. STA $1+445,34$

- Segmen $6 \quad$ : STA $1+445,34$ s.d. STA $1+700$

- Segmen 7 : STA $1+700$ s.d. STA 2+178

- Segmen $8 \quad$ :STA $2+178$ s.d. $2+564$

- Segmen 9 : STA $2+564$ s.d. STA 2+700

- Segmen 10 : STA 2+700 s.d. STA 3+000

Pembagian segmen ini didasarkan pada riwayat lapis ulang perkerasan landasan pacu Bandar Udara Juanda.
Data ketebelan lapis perkerasan diperoleh secara primer dengan menggunakan GPR (Geo Penetrating Radar). Rekapitulasi data primer tebal perkerasan dan daya dukung tanah dasar adalah dapat dilihat pada Tabel 1.

Tabel 1. Rekapitulasi Data Primer Tebal Perkerasan dan Daya Dukung Tanah Dasar

\begin{tabular}{ccccc}
\hline Segmen & $\begin{array}{c}\text { Surface } \\
\text { (inches) }\end{array}$ & $\begin{array}{c}\text { Base } \\
\text { Course } \\
\text { (inches) }\end{array}$ & $\begin{array}{c}\text { Subbase } \\
\text { (inches) }\end{array}$ & $\begin{array}{c}\text { Daya Dukung } \\
\text { Subgrade (\%) }\end{array}$ \\
\hline 1 & 25.49 & 11.81 & 59.06 & 3.76 \\
2 & 25.49 & 11.81 & 49.21 & 2.21 \\
3 & 25.49 & 19.69 & 41.34 & 2.92 \\
4 & 25.49 & 15.75 & 41.34 & 2.69 \\
5 & 25.49 & 17.72 & 53.15 & 1.23 \\
6 & 25.49 & 15.75 & 43.31 & 1.34 \\
7 & 15.99 & 9.84 & 59.06 & 1.95 \\
8 & 17.22 & 7.87 & 64.96 & 1.64 \\
9 & 17.22 & 7.87 & 51.18 & 1.48 \\
10 & 17.22 & 5.91 & 45.28 & 2.19 \\
\hline
\end{tabular}

Untuk data sekunder keberangkatan pesawat terbang dari Bandar Udara Juanda Tahun 2019 dapat dilihat pada Tabel 2. Sedangkan data keberangkatan pesawat dari Bandar Udara Juanda 5 (lima) tahun terakhir dapat dilihat pada Tabel 3. 
Tabel 2. Data Sekunder Keberangkatan Pesawat Terbang dari Bandar Udara Juanda Tahun 2019

\begin{tabular}{|c|c|c|c|}
\hline No. & Aircraft Name & $\begin{array}{c}\text { Gross } \\
\text { Weight (Lbs) }\end{array}$ & $\begin{array}{c}\text { Annual } \\
\text { Departure }\end{array}$ \\
\hline 1 & A300-600 & 380,518 & 6 \\
\hline 2 & A319-100 std & 141,978 & 6 \\
\hline 3 & A320 Neo & 175,047 & 115 \\
\hline 4 & A320 Twin opt & 172,842 & 21,067 \\
\hline 5 & A330-200 opt & 509,047 & 24 \\
\hline 6 & A330-300 opt & 515,661 & 1,579 \\
\hline 7 & A330-900NEO & 533,519 & 17 \\
\hline 8 & AN12 & 134,482 & 7 \\
\hline 9 & ATR42 500 & 41,006 & 3 \\
\hline 10 & ATR72 500 & 49,604 & 6,802 \\
\hline 11 & B737-200 & 128,600 & 2 \\
\hline 12 & B737-400 & 150,500 & 69 \\
\hline 13 & B737-500 & 134,000 & 2,425 \\
\hline 14 & B737-800 & 174,700 & 15,610 \\
\hline 15 & B737-900 ER & 188,200 & 12,118 \\
\hline 16 & B747-400ER & 910,002 & 350 \\
\hline 17 & B757-200 & 256,000 & 3 \\
\hline 18 & B767-200 & 317,000 & 4 \\
\hline 19 & B777-200 ER & 634,499 & 35 \\
\hline 20 & B777-300 ER & 650,364 & 103 \\
\hline 21 & B787-8 & 503,501 & 3 \\
\hline 22 & BAe 125 & 27,403 & 7 \\
\hline 23 & BAe 146 & 89,508 & 1 \\
\hline 24 & BAe Avro RJ85 & 93,013 & 3 \\
\hline 25 & $\mathrm{BBJ} 2$ & 171,500 & 2 \\
\hline 26 & Beech 1900 & 17,117 & 7 \\
\hline 27 & Beech 200 & 12,500 & 222 \\
\hline 28 & Beech 350 & 14,991 & 1 \\
\hline 29 & Beech 400 & 15,500 & 10 \\
\hline 30 & Bombardier GL5T & 88,185 & 20 \\
\hline 31 & Bombardier GLEX & 95,901 & 10 \\
\hline 32 & Bonanza S35 & 3,300 & 1 \\
\hline 33 & $\mathrm{C}-17 \mathrm{~A}$ & 585,000 & 4 \\
\hline 34 & Casa 212 & 16,976 & 1 \\
\hline 35 & Cessna 172 & 2,425 & 10 \\
\hline 36 & Cessna 208 & 8,598 & 258 \\
\hline 37 & Cessna 525 & 10,362 & 2 \\
\hline 38 & Cessna 560 & 15,873 & 3 \\
\hline 39 & Cessna 680 & 30,774 & 2 \\
\hline 40 & Cessna Caravan2 & 9,700 & 4 \\
\hline 41 & CL 60 & 42,990 & 15 \\
\hline 42 & CRJ 1000 & 92,301 & 2,024 \\
\hline 43 & DH8C Bombardier & 63,052 & 16 \\
\hline 44 & Eclipse 500 & 5,732 & 3 \\
\hline 45 & Embraer 505 Phenom & 17,527 & 39 \\
\hline 46 & ERJ 135 & 44,092 & 138 \\
\hline 47 & ERJ 190 & 105,359 & 8 \\
\hline 48 & Falcon 2000 & 35,000 & 4 \\
\hline 49 & Falcon $8 \mathrm{X}$ & 72,973 & 26 \\
\hline 50 & Falcon 900 & 45,500 & 1 \\
\hline 51 & Fokker 100 & 94,799 & 17 \\
\hline 52 & Fokker 27 & 44,974 & 1 \\
\hline
\end{tabular}

\begin{tabular}{clrr}
\hline 53 & Fokker 50 & 45,900 & 3 \\
54 & Gulfstream G150 & 26,250 & 19 \\
55 & Gulfstream G200 & 35,600 & 1 \\
56 & Gulfstream GLF4 & 75,000 & 3 \\
57 & Gulfstream GLF5 & 90,900 & 46 \\
58 & Gulfstream GLF6 & 99,649 & 5 \\
59 & Hawker 800XP & 28,120 & 3 \\
60 & Learjet LJ35 & 18,000 & 5 \\
61 & Learjet LJ45 & 21,499 & 21 \\
62 & Learjet LJ60 & 23,499 & 2 \\
63 & MD82 & 149,500 & 228 \\
64 & Piaggio P180 & 11,552 & 6 \\
65 & Pilatus PC6T & 6,173 & 2 \\
66 & Piper PA34 & 4,749 & 11 \\
67 & Socata TBM9 & 7,394 & 1 \\
68 & Westwind WW24 & 23,501 & 22 \\
\hline Sumber: PT. Angkasa Pura (Persero) & Bandar Udara Juanda
\end{tabular}

Tabel 3. Data Sekunder Keberangkatan Pesawat Terbang dari Bandar Udara Juanda Tahun 2015-2019 [7]

\begin{tabular}{|c|c|c|c|c|c|}
\hline \multirow{3}{*}{ Tahun } & \multicolumn{3}{|c|}{ Penerbangan } & \multicolumn{2}{|c|}{$\begin{array}{c}\text { Pertumbuhan } \\
(\%)\end{array}$} \\
\hline & & & Domestik & & \\
\hline & Domestik & $\begin{array}{c}\text { Inter } \\
\text { nasional }\end{array}$ & $\begin{array}{c}+ \\
\text { Inter } \\
\text { nasional }\end{array}$ & $\begin{array}{l}\text { Per } \\
\text { tahun }\end{array}$ & $\begin{array}{c}\text { Rata- } \\
\text { rata }\end{array}$ \\
\hline 2015 & 122,911 & 12,198 & 135,109 & & \multirow{5}{*}{-0.44} \\
\hline 2016 & 135,963 & 12,269 & 148,232 & 9.71 & \\
\hline 2017 & 135,892 & 12,673 & 148,565 & 0.22 & \\
\hline 2018 & 141,493 & 14,925 & 156,418 & 5.29 & \\
\hline 2019 & 114,597 & 15,266 & 129,863 & -16.98 & \\
\hline
\end{tabular}

Sebelum melakukan analisis ekivalen tebal perkerasan eksisting menjadi tebal perkerasan ekivalen FAA, terlebih dahulu dilakukan penyesuaian tebal lapis permukaan perkerasan eksisting akibat umur perkerasan. Berdasarkan informasi dari PT. Angkasa Pura (Persero) Bandar Udara Juanda, Segmen 1 s.d. Segmen 6 mengalami lapis ulang terakhir pada Tahun 2019. Sedangkan Segmen 7 s.d. Segmen 10 dilakukan lapis ulang terakhir pada Tahun 2012. Berhubung belum ada standar/aturan FAA yang mengatur penyesuaian tebal perkerasan karena usia lapis permukaan, maka untuk penyesuaian tebal perkerasan karena usia lapis permukaan pada makalah ini menggunakan Metode Indeks Tebal Perkerasan (ITP) pada perkerasan jalan [5]. Berdasarkan Metode ITP, indeks permukaan perkerasan saat awal (IPo) digunakan adalah 4 dan indeks permukaan perkerasan saat ini (IPt) diasumsikan sebesar 2,5 (artinya jalan dengan kondisi permukaan masih cukup baik pada akhir unur rencana 5-10 tahun) [2]. Jika dihitung selisih antara IPt dengan IPo, maka tebal perkerasan mengalami penurunan sebesar 37,5\% $(=((4$ $-2,5) / 4) * 100 \%$ ) selama umur rencana 5 tahun. Untuk Segmen 1 s.d. 6 belum mencapai umur rencana, maka nilai IPt 
akan dihitung secara proporsi selisih antara IPo dan IPt. Hasil analisis ekivalen tebal perkerasan eksisting menjadi tebal perkerasan ekivalen FAA dapat dilihat pada Tabel 4.

Tabel 4. Hasil Analisis Ekivalensi Standard FAA Tebal Perkerasan Eksisting

\begin{tabular}{cccc}
\hline Segmen & $\begin{array}{c}\text { Surface } \\
\text { (inches) }\end{array}$ & $\begin{array}{c}\text { Base Course } \\
\text { (inches) }\end{array}$ & $\begin{array}{c}\text { Subbase } \\
\text { (inches) }\end{array}$ \\
\hline 1 & 5 & 8 & 110,3 \\
2 & 5 & 8 & 100,4 \\
3 & 5 & 8 & 103,6 \\
4 & 5 & 8 & 98,1 \\
5 & 5 & 8 & 112,7 \\
6 & 5 & 8 & 100,1 \\
7 & 5 & 8 & 86,3 \\
8 & 5 & 8 & 92,2 \\
9 & 5 & 8 & 78,4 \\
10 & 5 & 8 & 68,7 \\
\hline
\end{tabular}

Analisis selanjutnya adalah analisis kekuatan struktur perkerasan landasan pacu dengan Software COMFAA. Salah satu parameter yang dijadikan dasar untuk mengetahui kekuatan perkerasan landasan pacu suatu bandar udara adalah pavement classification number (PCN). Pedoman untuk perhitungan PCN bandar udara di Indonesia mengacu kepada Peraturan Direktorat Jenderal Perhubungan Udara KP 93
Tahun 2015 [3] tentang Pedoman Perhitungan PCN Perkerasan Prasarana Bandar Udara. Secara garis besar, peraturan tersebut mengacu pada peraturan yang dikeluarkan oleh FAA, yakni Advisoary Circular (AC) 150/5335-5C [1] yang dikeluarkan oleh FAA pada tanggal 14 Agustus 2014. Di dalam AC 150/5335-5C disebutkan bahwa untuk mempermudah perhitungan PCN sebuah bandar udara, dapat menggunakan Software COMFAA.

Input data pada Software COMFAA adalah ekivalensi Standard FAA tebal perkerasan eksisting landasan pacu Bandar Udara Juanda dan data sekunder keberangkatan pesawat dari Bandar Udara Juanda Tahun 2019. Sedangkan output Software COMFAA adalah kebutuhan tebal perkerasan, PCN (Pavement Classification Number) dan ACN (Aircraft Classification Number). Perhitungan tebal minimum perkerasan bandar udara didasarkan pada Metode 6D dan CDF. Pavement Classification Number (PCN) adalah merupakan suatu angka yang menjelaskan daya dukung perkerasan untuk operasi tak terbatas pesawat udara dengan nilai ACN kurang dari atau sama dengan PCN. Sedangkan ACN adalah suatu nilai yang menunjukkan efek relatif sebuah pesawat terbang di atas pavement untuk kategori sub-grade standar yang ditentukan Contoh grafik output hasil analisis kekuatan struktur perkerasan eksisting dapat dilihat pada Gambar 4 dan Gambar 5.

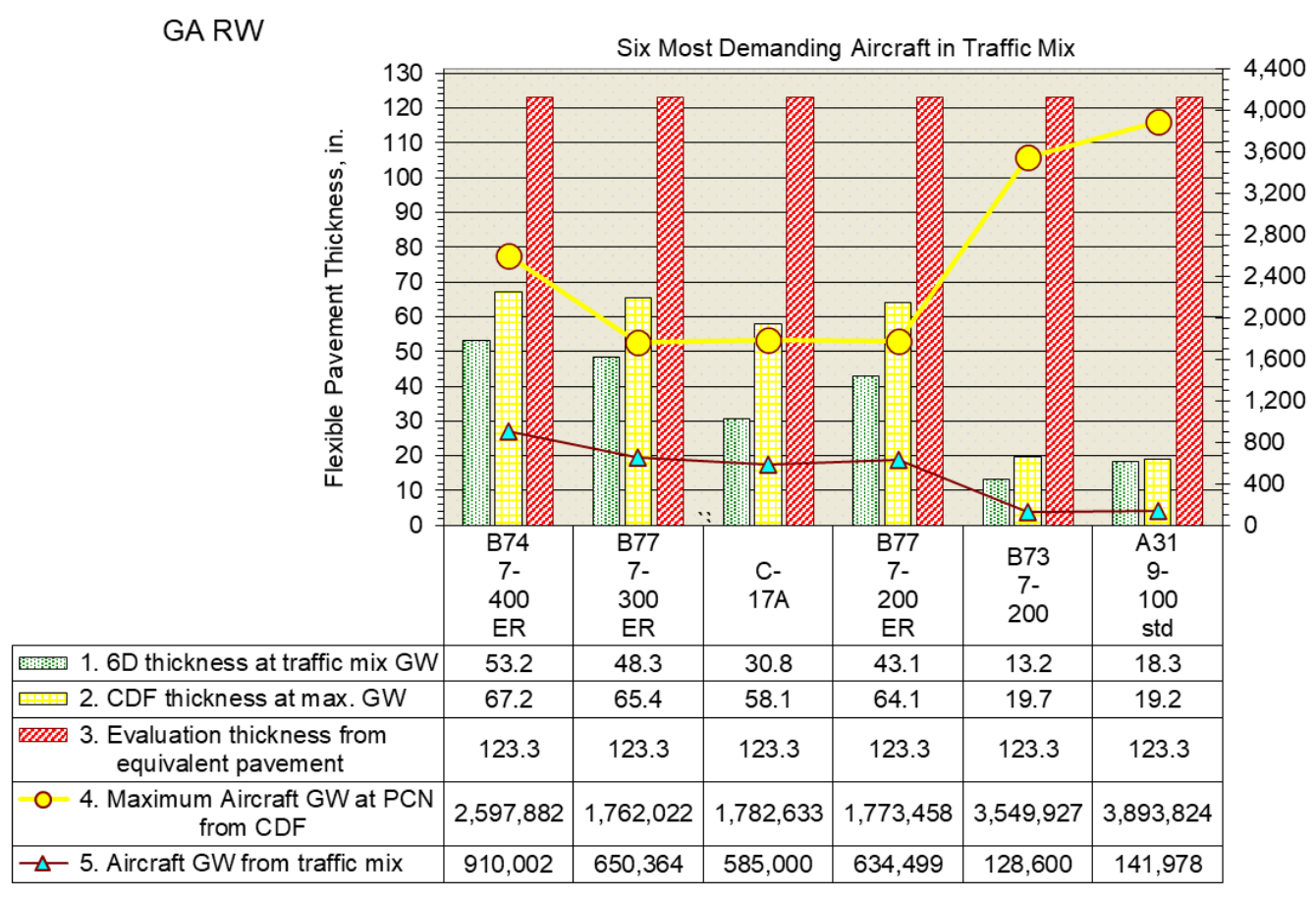

Gambar 4. Grafik Perhitungan Kebutuhan Tebal Minimum Perkerasan Landasan Pacu Bandar Udara Juanda Segmen 1 
GA RW

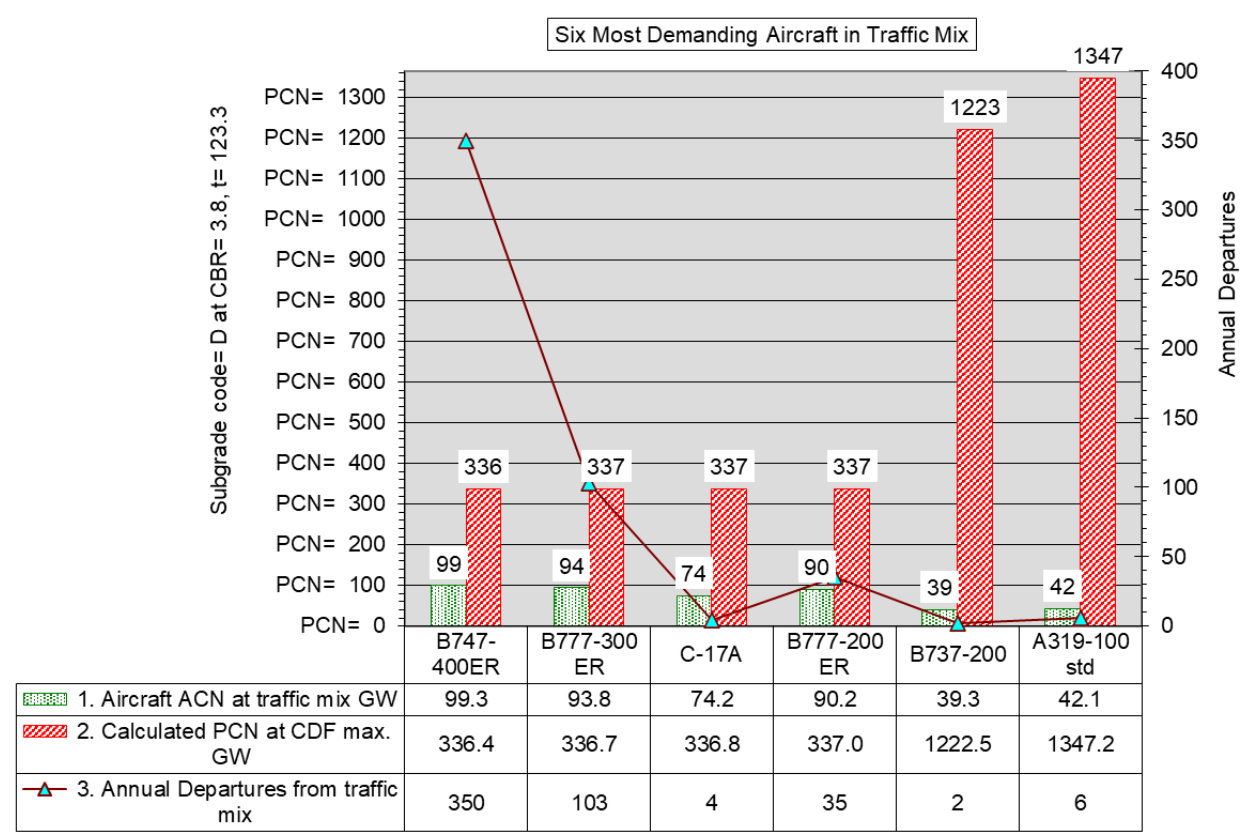

Gambar 5. Grafik Perhitungan Nilai PCN Perkerasan Eksisting Landasan Pacu Bandar Udara Juanda dan Nilai ACN Pesawat Terbang Yang Berangkat dari Bandar Udara Juanda Skenario 1

Rekapitulasi hasil analisis kebutuhan tebal minimum, ACN tiap type pesawat dan nilai PCN perkerasan eksiting landasan pacu Bandar Udara Juanda adalah sebagai berikut:

a. Segmen 1:

- Tebal perkerasan eksisting

$=123,3$ inches

- $6 D$ thickness at traffic mix $G W=53,2$ inches (B747-400 ER)

- CDF thickness at max $G W=67,2$ inches ((B747-400 ER)

- ACN at traffic mix GW = 99,3 (B747400 ER)

- Calculated PCN at CDF max GW = 336,4 (B747400 ER)

b. Segmen 2:

- Tebal perkerasan eksisting =113,4 inches

- $6 D$ thickness at traffic mix $G W \quad=71,3$ inches (B777-300 ER)

- CDF thickness at max $G W \quad=97,7$ inches (A300-600)

- ACN at traffic mix $G W \quad=96,7$ (A330-300 Opt)

- Calculated PCN at CDF max $G W=354,4$ (A330300 Opt)

c. Segmen 3:

- Tebal perkerasan eksisting = =116,6 inches
- $6 D$ thickness at traffic mix $G W \quad=58,5$ inches (B777-300 ER)

- CDF thickness at max $G W \quad=77,8$ inches (B777-300 ER)

- ACN at traffic mix GW =94,3 (A300600)

- Calculated PCN at CDF $\max G W=186,8$ (A300600)

d. Segmen 4:

- Tebal perkerasan eksisting = $=111,1$ inches

- $6 D$ thickness at traffic mix $G W \quad=62,3$ inches (B777-300 ER)

- CDF thickness at max $G W \quad=88,0$ inches (A300-600)

- ACN at traffic mix GW $\quad=94,3(\mathrm{~A} 300-$ 600)

- Calculated PCN at CDF $\max G W=154$ (A300600)

e. Segmen 5:

- Tebal perkerasan eksisting = 125,7 inches

- $6 D$ thickness at traffic mix $G W \quad=119,4$ inches (A330-300 Opt)

- CDF thickness at max GW= =123,4 inches (B777-300 ER)

- ACN at traffic mix $G W \quad=106,3(\mathrm{~B} 787-8)$

- Calculated PCN at CDF max GW =117,4 (B787-8) 
f. Segmen 6:

- Tebal perkerasan eksisting $=113,1$ inches

- $6 D$ thickness at traffic mix $G W$ (A330-300 Opt)

- CDF thickness at max $G W \quad=113,7$ inches (A330-300 Opt)

- ACN at traffic mix $G W$ $=106,3(\mathrm{~B} 787-$ 800)

- Calculated PCN at CDF max GW = 105,1 (B787800)

g. Segmen 7:

- Tebal perkerasan eksisting $\quad=99,3$ inches

- $6 D$ thickness at traffic mix $G W \quad=90,8$ inches (A330-300 Opt)

- CDF thickness at max $G W \quad=96,8$ inches (A300-600)

- ACN at traffic mix $G W \quad=106,3(\mathrm{~B} 787-8)$

- Calculated PCN at CDF max GW =126,2 (B787-8)

h. Segmen 8:

- Tebal perkerasan eksisting $\quad=105,2$ inches

- $6 D$ thickness at traffic mix $G W \quad=101,2$ inches (A330-300 Opt)

- CDF thickness at max $G W \quad=103,8$ inches (A300-600)

- $A C N$ at traffic mix $G W \quad=106,3(\mathrm{~B} 787-8)$

- Calculated PCN at CDF $\max G W=114,1$ (B787-8)

i. Segmen 9:

- Tebal perkerasan eksisting $\quad=91,4$ inches

- $6 D$ thickness at traffic mix $G W \quad=95,7$ inches (B747-400ER)

- CDF thickness at max $G W \quad=109,2$ inches (A330-900NEO)

- ACN at traffic mix $G W \quad=106,3(\mathrm{~B} 787-8)$

- Calculated PCN at CDF max GW = 72 (B787-8)

j. Segmen 10:

- Tebal perkerasan eksisting $\quad=82,7$ inches

- $6 D$ thickness at traffic mix $G W \quad=84,0$ inches (A330-300 Opt)

- CDF thickness at max $G W=84,9$ inches (A330-900NEO)

- ACN at traffic mix $G W \quad=106,3(\mathrm{~B} 787-8)$

- Calculated PCN at CDF max GW =101,0 (B787-8)

Dari hasil analisis, struktur perkerasan landasan pacu segmen 1 s.d. segmen 4 lebih tebal dibanding kebutuhan tebal minimum hasil perhitungan dengan Software COMFAA. Selisih antara tebal perkerasan eksisting dengan kebutuhan minimum hasil perhitungan Software COMFAA sangat signifikan, dimana terbesar pada segmen 1 yakni sebesar 70,1 inch. Selisih yang sangat signifikan juga ditemui pada PCN dan ACN segmen 1 s.d. segmen 4.

Pada segmen 5, 7 dan 8 mempunyai karakteristik hasil yang sama, dimana struktur perkerasan landasan pacu eksisting lebih tebal dibanding kebutuhan tebal minimum hasil perhitungan dengan Software COMFAA. Namun selisih tebalnya tidak terlalu sginifikan. Demikian juga pada perbandingan antara PCN dan ACN pada segmen 5, 7 dan 8, selisih nilainya tidak signifikan.

Untuk tebal perkerasan landasan pacu eksisiting pada segmen 6. 9 dan 10 lebih kecil dibandingkan dengan tebal perkerasan hasil perhitungan Software COMFAA. Pavement Classification Number (PCN) lebih kecil dibanding ACN. Diduga hal ini disebabkan karena daya dukung tanah dasar pada segmen 6, 9 dan 10 sangat rendah serta struktur tebal perkerasannya relatif lebih tipis/kecil.

\section{Simpulan}

Kebutuhan tebal perkerasan pada landasan pacu Bandara Juanda masih bisa dicukupi oleh perkerasan eksisting kecuali pada segmen 6, 9 dan 10. Namun pada segmen 5, 7 dan 8; selisih antara tebal perkerasan eksisting dengan kebutuhan tebal perkerasan adalah kecil/sedikit.

Jika membandingkan output $\mathrm{PCN}$ dan ACN pada masingmasing segmen sebagai salah satu parameter kekuatan struktur perkerasan, maka diperoleh hasil relatif sama dengan output kebutuhan tebal perkerasan pada masing-masing segmen. Nilai PCN pada segmen 1 s.d. 4 lebih besar dibanding ACN, nilai PCN segmen 5, 7 dan 8 lebih besar dibanding ACN, namun selisihnya kecil/sedikit. Sedangkan untuk PCN segmen 6, 9 dan 10 lebih kecil/rendah dibanding ACN. Sehingga disarankan pada segmen 5 s.d. 10 untuk segera dilapis ulang atau diberlakukan pembatasan berat pesawat saat lepas landas (maximum take-off weight).

\section{Daftar Pustaka}

[1] AC No: 150/5335-5C, "Standardized Method of Reporting Airport Pavement Strength - PCN," Area, no. August, pp. 1-4, 2014, [Online]. Available: https://www.faa.gov/documentLibrary/media/Adviso ry_Circular/150-5335-5c.pdf.

[2] Departemen Pekerjaan Umum, Petunjuk Perencanaan Tebal Perkerasan Lentur Jalan Raya Dengan Metode Analisa Komponen, vol. 73, no. 02. 1987.

[3] K. P. Direktorat Jenderal Perhubungan Udara, Pedoman Teknis Operasional Peraturan Keselamatan Penerbangan Sipil Bagian 139-24, vol. 24. 2015.

[4] K. P. Direktorat Jenderal Perhubungan Udara, Pedoman Teknis Operasional Peraturan Keselamatan 
Penerbangan Sipil Bagian 139-23 \{Advisory Circular CASR PART 139-23), Pedoman Program Pemeliharaan Konstruksi Perkerasan Bandar Udara (Pavement Management System). Indonesia, 2015.

[5] I. Istiar, I. B. Mochtar, W. Herijanto, and C. A. Prastyanto, "Taxiway Pavement Evaluation to Support the Operational of Terminal 2 Juanda Airport," IPTEK J. Proc. Ser., vol. 3, no. 6, 2017, doi: 10.12962/ j23546026.y2017i6.3314.

[6] F. Kristiawan, E. Ahyudanari, and I. Istiar, "Evaluasi Kesesuaian Jadwal Pemeliharaan Runway dengan Pertumbuhan Pergerakan Pesawat di Bandar Udara Juanda," J. Tek. ITS, vol. 6, no. 2, pp. 2-6, 2018, doi: 10.12962/j23373539.v6i2.26130.

[7] PUSTIKOMHUB, Statistik Perhubungan 2018, vol. 53, no. 9. 2019. 